\title{
Selection of Design Concept: A case study
}

\author{
S.S.Kalashetty ${ }^{1}$, Dr.G.K.Purohit ${ }^{2}$ and Dr.S.S.Hebbal ${ }^{3}$ \\ ${ }^{I}$ PhD. student, Mech. Engg. Dept.,PDA Engg.college Gulbarga, India \\ ${ }^{2}$ Prof. and Head, Mech.Engg., PDA Engg.college Gulbarga, India \\ ${ }^{3}$ Principal, PDA Engg.college Gulbarga, India
}

\begin{abstract}
Concept is concise description of how the product will satisfy the customer requirements. Selecting right design concept at conceptual design stage in the product development process is crucial decision. Inaccurate design can cause the product to be redesigned or remanufactured. Analytical Hierarchy Process $(A H P)$ is one of the useful tools that can be employed in determining the most appropriate design concept. AHP is a multi-criteria decision making tool which is based on the pairwise comparison of elements of a given set with respect to multiple criteria. This article presents a systematic method for the selection of best sprayer design concept among three alternatives, using Analytical Hierarchy Process (AHP). The problem is modeled on the basis of hierarchy containing the decision goal, the criteria (requirements), sub-criteria and alternatives. A series of judgments based on pairwise comparisons of the elements are made to establish the priorities among the elements. These judgments are synthesized to yield a set of overall priority of the hierarchy and the judgments were checked for consistency. Finally selection of design concept is made on the results of the process
\end{abstract}

Key words - AHP, Criteria, multi-criteria decision making, pairwise comparison, sprayer design concept

\section{Introduction}

A product concept is an approximate description of the technology, working principles and form of the product. It is concise description of how the product will satisfy the customer requirements. A concept is usually expressed as a sketch or a rough three dimensional model. The degree to which a product satisfies customer and can be successfully commercialized, depends to a large extent on the underlying concept. A good concept is sometimes poorly implemented in subsequent development phases, but a poor concept can rarely be manipulated to achieve commercial success. One of the early stages of product development process is called conceptual design stage. The conceptual design stage is an initial stage of the product development process which has been identified as the most crucial for the successful introduction of new products $[6,12]$. Selecting the right design concepts at the conceptual design stage in product development process is a crucial decision [5, 16]. Implementing appropriate evaluation and decision tool should be considered at the conceptual design stage that involves many complex decision-making tasks [15]. Conceptual design of product development process is a preliminary stage of design activities because various decision making problems are addressed at this stage, for example materials selection, design concept selection and manufacturing process selection. Therefore, considering the right decision at this stage is very important and critical. It is because the overall success of the product as once the conceptual design process has been completed, the majority of product cost and quality has been fixed by selecting particular concepts [11]. One of the useful tools that can be employed at the conceptual design stage is Analytical Hierarchy Process (AHP). It is a powerful and flexible weighted scoring decision making process to help people set priorities and make the best decision [6]

A set of customer requirements were identified in the early development process of the sprayer [13]. Then three alternative solution concepts were generated to these requirements. This paper presents the evaluation of concepts with respect to customer requirements and other criteria, comparing relative strengths and weaknesses of the concepts using AHP. One of the useful tools that can be employed in determining the most appropriate design concept is Analytical Hierarchy Process. This process can assist to effectively evaluate various conceptual design alternatives.

\section{Analytical hierarchy process (AHP)}

The Analytic Hierarchy Process (AHP) is a structured mathematical technique for multi-criteria decision making. It enables people to make decisions involving many kinds of concerns including planning, setting priorities, selecting the best among a number of alternatives, and allocating resources. Thomas Saaty developed the analytical hierarchy process to be an effective means of dealing the complex decision making [1, 10]. AHP helps to capture both subjective and objective evaluation measures. The basic problem of decision making is to choose the best one from a set of competing alternatives that are evaluated under conflicting 
criteria [16]. A multi-criteria problem may be affected by various visible / invisible qualitative and quantitative factors such as the functions, aesthetics, safety, cost, operation, reliability etc. Hence use of a systematic method to evaluate the priorities among the related factors is necessary. The AHP provides a comprehensive framework for solving such problems. Further AHP can be successfully combined with Quality Function Deployment (QFD) in the development of new product, manufacturing, tooling process selection [9], IT industry [2]. The basic principle of the AHP is to decompose the complex issue with various factors and form a hierarchy of more easily comprehended sub-problems and then to calculate the weight vectors of multi-level and multi-index factors qualitatively and quantitatively based on the experience. The core of AHP is to use integers from 1 to 9 and their reciprocals to construct a comparison matrix [17]. Under the condition that the comparison matrix is consistent, first the weight ordering of factors in each level is obtained, and synthesized into overall weight ordering of all the choices with respect to the final goal, the overall weight is used to arrive at the best design possible.

\section{Pesticide sprayer criteria}

Pigeon pea is a principal commercial crop of Gulbarga region of Karnataka state in India. Pest attack is a major threat to this crop. Helicoverpa armigera is the most important pest on pigeonpea and the last decade has witnessed three outbreaks of this pest resulting in $10-80 \%$ crop loss due to this pest [7]. Hence it is imperative to prevent the pest from attacking the crop. Agrochemicals are used to spray on to the crop to protect it from the pests and insects. Pigeon pea growers use different types of sprayers for the management of the pest. Successful pest management depends not only on the quality of the pesticide and insecticides but also the use of right plant protection appliances. Several insecticides newer molecules, botanicals and bioagents are most promising against the pests and insects but efficacy has been limited due to lack of application technology in particular the sprayers employed under field condition [3]. But presently available sprayers used for spraying on to the crop are having their own drawbacks [14]. A survey conducted in this pigeon pea growing region revealed that the customers (farmers, sprayer operators, owners) were having a desire of new user friendly sprayer. Hence a research work has been undertaken to design a sprayer based on customer requirements. Generation and selection of sprayer design concepts are part of this design process. This paper deals with the selection of design concept using AHP.

Three concepts $\mathrm{C}-1, \mathrm{C}-2$ and $\mathrm{C}-3, \mathrm{C}-4$ considered for selection are shown in Fig. 1, Fig.2 and Fig. 3 In all the concept solution tank is same. Concept $\mathrm{C}-1$ is having one spray head where as $\mathrm{C}-2$ and $\mathrm{C}-3$ are having two spray heads, solar panel and battery of higher capacity.

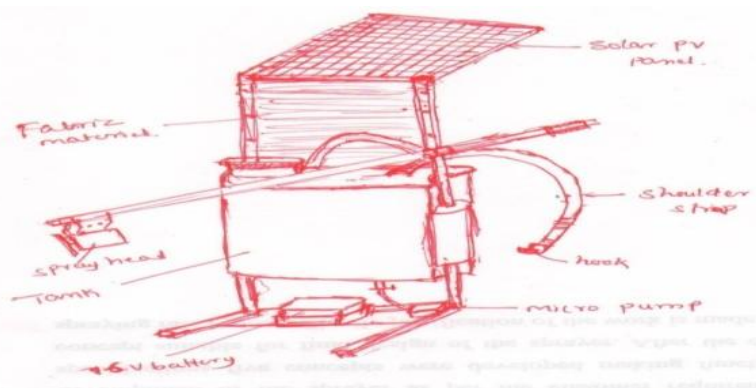

Figure 1 Concept 1

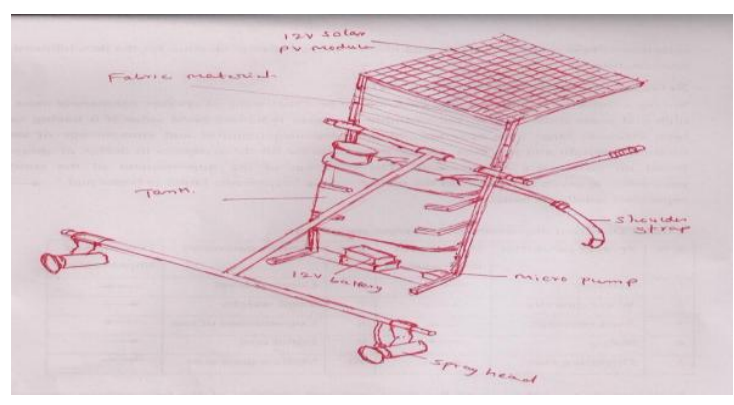

Figure 2 Concept $\mathbf{C}$ - 2

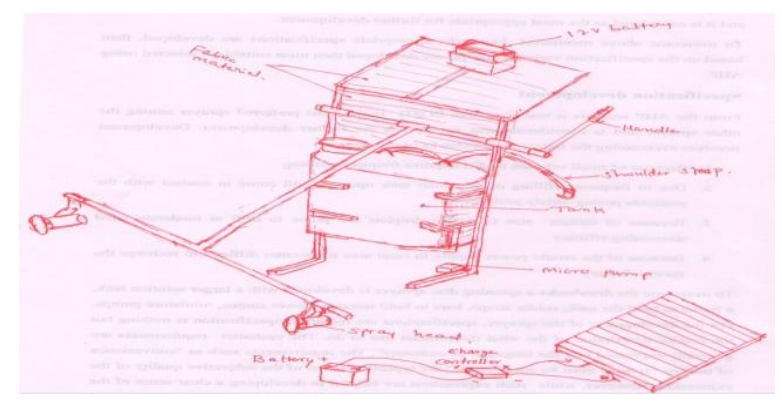

Figure 3 Concept $\mathbf{C}-3$ 
Table 1 Value of the qualitative criteria of various sprayer concepts

\begin{tabular}{|c|c|c|c|}
\hline Sprayer concept/Criteria & $\mathrm{C}-1$ & $\mathrm{C}-2$ & $C-3$ \\
\hline Efficacy & High & Very high & Very high \\
\hline Water quantity & Very high & Very high & Very high \\
\hline Area covered & Moderate & High & High \\
\hline \multicolumn{4}{|l|}{ Ergonomics } \\
\hline Total weight & High & Very low & Low \\
\hline Comfort level & High & Low & Moderate \\
\hline Safety & Very high & Very high & Very high \\
\hline Convenience of use & Very high & Very high & High \\
\hline \multicolumn{4}{|l|}{ Total cost } \\
\hline Initial cost & High & Low & Very low \\
\hline Operating cost & Very high & High & High \\
\hline Maintenance cost & Very high & High & High \\
\hline
\end{tabular}

\section{Implementation of AHP}

The AHP methodology of selecting concept involves the following steps.

\subsection{Step 1: Construction of the model.}

First all the factors are classified in to groups. Each group is called a level. Then they are arranged in order according to goal level, criteria level, sub-criteria level and scheme level. Figure 1 shows a hierarchy model for decision making. The highest level stands for the goal of the decision. The middle levels stand for the midst links and are usually consisting of criterion level, sub-criterion level and scheme level. The lowest level stands for alternative schemes.

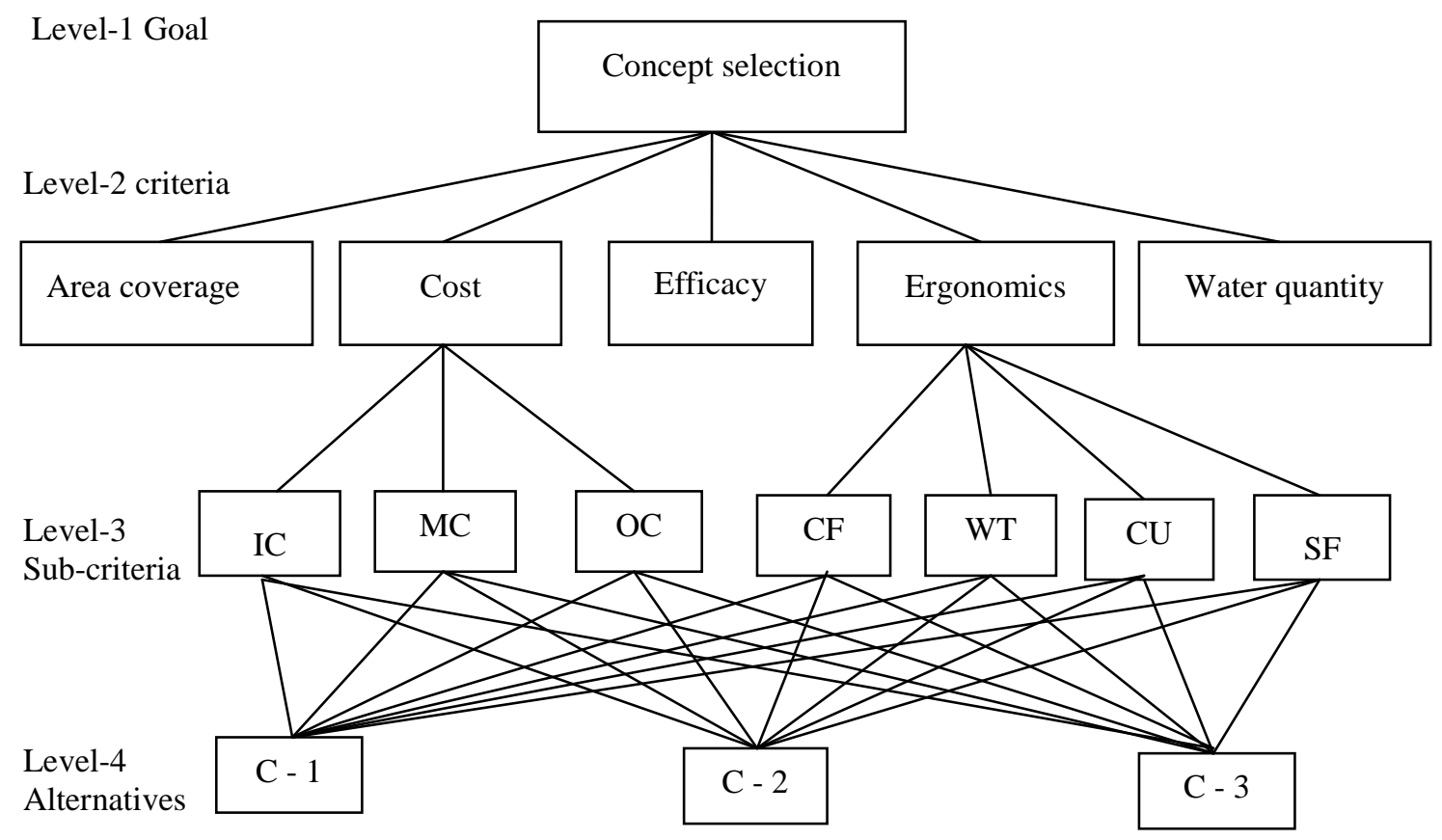

Figure 4 AHP level models for the concept selection 


\subsection{Step 2: Construction of pair-wise comparison matrix}

The comparison matrix gives the relative importance of the factors in the current level with respect to some factors in higher level. It is usually given by pair-wise comparisons [8]. The number of matrices depends on the number of elements at each level. The order of the matrix at each level depends on the number of elements at the level that it links to. Pair-wise comparison begins with comparing the relative importance of two selected items. The judgments are decided based on the decision makers or users experience and knowledge. The decision makers have to compare or judge each element by using the Saaty's relative importance 1-9 point scale as shown in Table 2. The scale used for comparing in AHP enables the decision makers to incorporate experience and knowledge intuitively. For example in Table 3 pair-wise comparison matrices if efficacy is much more important than cost then a weightage of 5 is given to efficacy with respect to cost. Reciprocals are automatically assigned to each pair-wise comparison.

Table 2 Saaty's relative importance scale

\begin{tabular}{|c|l|l|}
\hline $\begin{array}{c}\text { Intensity } \\
\text { of } \\
\text { importance }\end{array}$ & \multicolumn{1}{|c|}{ Definition } & \multicolumn{1}{c|}{ Explanation } \\
\hline 1 & Equal importance & Two factors contribute equally to the objective \\
\hline 3 & $\begin{array}{l}\text { Somewhat more } \\
\text { important }\end{array}$ & Experience and judgment slightly favor one over the other. \\
\hline 5 & $\begin{array}{l}\text { Much more } \\
\text { important }\end{array}$ & $\begin{array}{l}\text { Experience and judgment strongly favor one over } \\
\text { the other. }\end{array}$ \\
\hline 7 & $\begin{array}{l}\text { Very much more } \\
\text { important }\end{array}$ & $\begin{array}{l}\text { Experience and judgment very strongly favor one over the other. } \\
\text { Its importance is demonstrated in practice }\end{array}$ \\
\hline 9 & $\begin{array}{l}\text { Absolutely more } \\
\text { important }\end{array}$ & $\begin{array}{l}\text { The evidence favoring one over the other is of the } \\
\text { highest possible validity }\end{array}$ \\
\hline $2,4,6,8$ & $\begin{array}{l}\text { Intermediate } \\
\text { values }\end{array}$ & When compromise is needed \\
\hline
\end{tabular}

Table 3 Pair-wise Comparison of criteria with respect to overall goal

\begin{tabular}{|l|c|c|c|c|c|}
\hline Goal & EF & W & A & E & C \\
\hline Efficacy (EF) & 1 & 3 & 3 & 3 & 5 \\
\hline Water quantity (W) & $1 / 3$ & 1 & 1 & 3 & 5 \\
\hline Area covered (A) & $1 / 3$ & 1 & 1 & 2 & 5 \\
\hline Ergonomics (E) & $1 / 3$ & $1 / 3$ & $1 / 5$ & 1 & 7 \\
\hline Cost (C) & $1 / 5$ & $1 / 5$ & $1 / 5$ & $1 / 7$ & 23.000 \\
\hline Total column & 2.200 & 5.533 & 5.700 & 9.142 & 2 \\
\hline
\end{tabular}

\subsection{Step 3: Synthesizing the pair-wise comparison}

This step involves evaluation of the vectors of priorities and overall priority vector. The method of calculating the eigenvalue is used to evaluate the vectors of priorities of the elements. The priorities of the elements in lower levels in the hierarchy are first calculated and then it progresses to get overall priority vector. In addition to eigenvalue method for exact solution the average of normalized column (ANC) method is used [10]. This is a method of averaging over normalized columns. In mathematics priorities can be calculated as

$$
\begin{aligned}
& \frac{1}{n} \sum_{j=1}^{n} \frac{a_{i j}}{\sum_{i}^{n} a_{i j}}, \mathrm{i}, \mathrm{j}=1,2, \ldots \ldots . \mathrm{n}-1 . \\
& \mathrm{a}_{\mathrm{ij}}=\text { Numerical equivalent of the comparison between } \mathrm{i} \text { and } \mathrm{j} \\
& \mathrm{n}=\text { Number of criteria }
\end{aligned}
$$

\subsection{Step 4: Evaluation of the consistency}

Since the comparisons are made through personal or subjective judgments, some degree of inconsistency may be occurred. To guarantee the judgments are consistent, the final operation called consistency 
verification, which is regarded as one of the most advantages of the AHP. The consistency ratio (CR) is used to estimate the consistency of the judgments among the pair-wise comparisons. It is defined as

$$
\mathrm{CR}=\frac{\mathrm{CI}}{\mathrm{CR}}
$$

Where CI is called the consistency index which is defined as $\mathrm{CI}=\frac{\lambda_{\max }-\mathrm{n}}{\mathrm{n}-1}$

Where $\lambda_{\max }$ represents the maximum or principal eigenvalue of the pair-wise comparison matrix and $n$ represents size of the matrix. The closer $\lambda_{\max }$ is to $\mathrm{n}$ the more consistent is the judgment matrix. The notation RI is a statistical number obtained by Oak Ridge National laboratory [14]. The average random indices for different orders are given Table 4. If the CR is less than 0.1, the judgment matrix is consistent and acceptable. However If CR $>0.1$, the judgment matrix is inconsistent and the judgments should be reviewed and improved to obtain a consistent matrix.

Table 4 Random inconsistency index

\begin{tabular}{|c|c|c|c|c|c|c|c|c|c|c|c|c|}
\hline $\mathrm{N}$ & 1 & 2 & 3 & 4 & 5 & 6 & 7 & 8 & 9 & 10 & 11 & 12 \\
\hline $\mathrm{RI}$ & 0.00 & 0.00 & 0.58 & 0.90 & 1.12 & 1.24 & 1.32 & 1.41 & 1.45 & 1.49 & 1.51 & 1.58 \\
\hline
\end{tabular}

\section{Results}

MATLAB software was used along with AHP software to calculate the eigenvectors for all comparison matrices to yield a set of overall priority for the hierarchy and checked the consistency of the judgments. The elements in table 3 show the overall priority vector for criteria. The elements in table 5 represent the overall priority vector for alternatives with respect criteria and CRs are given in Table 6.

Table 5 Overall priority vector for the various concepts W.R.T. criteria

\begin{tabular}{|l|c|c|c|c|c|c|}
\hline Criteria/ & Efficacy & $\begin{array}{c}\text { Water } \\
\text { quantity } \\
\text { Concept }\end{array}$ & $\begin{array}{c}\text { Area } \\
\text { coverage } \\
\mathbf{0 . 1 9 0 0}\end{array}$ & Ergonomics & Cost & Priority \\
\hline C-1 & 0.2000 & 0.3333 & 0.1429 & 0.4517 & $\mathbf{0 . 0 4 1 8}$ & \\
\hline C-2 & 0.4000 & 0.3333 & 0.4286 & 0.2586 & 0.5818 & $\mathbf{0 . 2 6 8 1}$ \\
\hline C-3 & 0.4000 & 0.3333 & 0.4286 & 0.2897 & 0.1757 & $\mathbf{0 . 3 6 5 2}$ \\
\hline
\end{tabular}

Table 6 Consistency ratios (CR) for main criteria

\begin{tabular}{|l|cccccc|}
\hline Criteria & Water & Area & Efficacy & Cost & Ergonomics & Goal \\
\hline CR & 00 & 00 & 0.038 & 00 & 0.012 & 0.088 \\
\hline
\end{tabular}

\section{Conclusion}

Analytical Hierarchy Process is effectively used to select the best sprayer concept among the five alternatives. Concept $\mathrm{C}-3$ has ranked first with a score of 0.3667 (or $36.67 \%$ ) followed by concepts $\mathrm{C}-2$ and $\mathrm{C}-1$ with scores of 0.3652 and 0.2681 respectively. The difference between the scores of $\mathrm{C}-2$ and $\mathrm{C}-3$ concepts is very small because customer has given highest preference to efficacy (score 0.4169 ) followed by water quantity (score 0.2152 and area coverage (score 0.1900 ) respectively and the concepts $\mathrm{C}-2$ and $\mathrm{C}-3$ are having same priority with respect to these criteria. But when ergonomics is considered concept $\mathrm{C}-3$ is having an edge over other concepts. Hence C - 3 is selected as the best concept for further design and development of the pesticide sprayer based on customer's requirements. Since the consistency rations (CRs) are less than 0.1 all the judgments based on pairwise comparison are found to be consistent and acceptable.

\section{References}

[1]- Alessandro Perego, Andrea Rangone, (1996), On integrating tangible and intangible measures in AHP application a reference framework, IEEE international conference on systems, man and cybermetics, pp. 1836-1841(14)

[2]- Bhruga c. (1998), Structuring and weighing criteria decision making, Proceedings of the $13^{\text {th }}$ International conference on multiple criteria decision making, pp.229-242(11)

[3]- D.K.Siddesgouda, B.V.patil and Suhas Yelshetty, (2007), Performance of different sprayers against gram pod borer, Helicoverpa armigera(Hubner) on chickpea, Karnataka J. Agric. Sci., 20(2), pp.261-264

[4]- Hambali Ariff, mohd. Sapuan Salit, Napsiah Ismail and Y. Nukman (2009), Application of AHP in the design concept selection of automotive composite bumper beam during the conceptual design stage,Scientific reaserch and essay vol.4(4), pp. 198-211(6) pp.125-129.

[5]- Hambali Ariff, mohd. Sapuan Salit, Napsiah Ismail and Y. Nukman,(2008) Use of analytical hierarchy process (AHP) for selecting the best design concept, Journal teknologi,49 (a) dis. 2008: pp.1-18(1)

[6]- Hollins, W. and Pugh, S. 1990. Successful Product Design: What to do and When, London: Butterworths 
[7]- J.B.Gopali, Raju Teggelli, D.M.Mannur and Suhas Yelshetty, (2009), Evaluation of different spraying systems in the dispersal of HaNPV in pigeon pea, Karnataka J. Agric. Sci., 22(3-spl. Issue), pp.504-506

[8]- Jun YE, Xin-sheng Ma, Li Yang, (2008) Design and realization of AHP Toolbox in MATLAB, IEEE international conference on granular computing. pp.740-745

[9]- Nagahanumayya, B.Ravi and N.P.Mukharjee, (2006), Rapid hard tooling process selection using QFD-AHP methodology, Journal of technology management, Vol. 17, No. 3, pp.332-350(13)

[10]- Nan tu,Tian Zhang and Qiuyun He, Haofeng Zhang and Yahui Li,(2011) Applying Combined AHP-QFD Method In New Product Development, A case study in developing new sports earphone, IEEE international conference on management science and industrial engineering (MISIE) pp.80-85(8)

[11]- Rehman, F and Yan, X.T. 2003. Product design elements as means to realise functions in mechanical conceptual design. Proceedings of the International Conference on Engineering design ICED 03, pp. 1-10.

[12]- Riedal, J.C.K.H. and Pawar, K.S .(1997). The consideration of production aspects during product design stages. Integrated Manufacturing Systems, Volume 8, pp 208-214.

[13]- S.S.Klashetty, Dr.G.K.Purohit, Dr.S.S.Hebbal Elicitation and Prioritization of Requirements of Pesticide Sprayers, International Journal of Multidisciplinary Research and Advances in Engineering(IJMRAE), Vol.4, No. II, April 2012,

14- S.S. Kalashetty and S.S. Hebbal, (2005). Use of cam mechanism in the design of farm sprayer, National Conference on Industrial Problems on Machines and Mechanisms, IIT Kharagpur

[15]- Thomas L.Saaty, (1990), How to make a decision: The analytical hierarchy process, European journal of operation research 48 pp. $9-26$

[16]- V. Laemlaksakul, S. Bangsarantrip, (2008) Analytic Hierarchy Process for design selection of Laminated Bamboo Chair, Proceedings of the international multi conference of engineers and computer Scientists Volume II pp.1-6(7)

[17]- Xu, L., Z. Li., L. Shancang and T. Fengming. (2007), A Decision Support System for Product Design in Concurrent Engineering. Journal of Decision Support Systems. 42: 2029-2042. 